\title{
Kinship, association, and social complexity in bats
}

\author{
Gerald S. Wilkinson ${ }^{1}$ (D) $\cdot$ Gerald Carter $^{2,3,4} \cdot$ Kirsten M. Bohn $^{5} \cdot$ Barbara Caspers $^{6} \cdot$ Gloriana Chaverri $^{7}$. \\ Damien Farine ${ }^{2,3} \cdot$ Linus Günther $^{8} \cdot$ Gerald Kerth $^{9} \cdot$ Mirjam Knörnschild $^{8,10,11} \cdot$ Frieder Mayer $^{8} \cdot$ Martina Nagy $^{10}$. \\ Jorge Ortega $^{12} \cdot$ Krista Patriquin $^{13}$
}

\begin{abstract}
Among mammals, bats exhibit extreme variation in sociality, with some species living largely solitary lives while others form colonies of more than a million individuals. Some tropical species form groups during the day that persist throughout the year while many temperate species only gather into groups during hibernation or parturition. How groups form and then persist has now been described for a number of species, but the degree to which kinship explains patterns of association has never been quantified across species. Here, we use social network analysis and genetic data to determine the extent to which relatedness contributes to associations among individuals estimated from free-ranging animals across nine species from four families of bats. Network analysis reveals that all species show evidence of emergent social structure. Variation in the strength of the relationship between genetic relatedness and social association appears to be related to the degree of roost switching, i.e., species in which individuals change roosts frequently tend to exhibit higher levels of association among relatives. Sex-biased dispersal determines whether associations were between male or female relatives. The strength of associations among kin does not predict known occurrence of complex behaviors, such as dominance or various types of cooperation, indicating that kinship is not a prerequisite for social complexity in bats.
\end{abstract}

\section{Significance statement}

The number of differentiated relationships has been proposed as a way to measure social complexity. Among primates, relationships can be differentiated on the basis of rank, age, kinship, or association. Application of this approach to other groups of mammals that vary in sociality could help reveal ecological, behavioral, or cognitive similarities and differences between species.

Gerald S. Wilkinson

wilkinso@umd.edu

1 Department of Biology, University of Maryland, College Park, MD, USA

2 Department of Collective Behaviour, Max Planck Institut für Ornithologie, Konstanz, Germany

3 Department of Biology, University of Konstanz, Konstanz, Germany

4 Department of Evolution, Ecology, and Organismal Biology, The Ohio State University, Columbus, OH, USA

5 Department of Psychological and Brain Sciences, Johns Hopkins University, Baltimore, MD, USA
6 Department of Animal Behaviour, Bielefeld University, Bielefeld, Germany

7 Recinto de Golfito, Universidad de Costa Rica, Golfito, Costa Rica

8 Museum für Naturkunde, Berlin, Germany

9 Zoologisches Institut und Museum, Greifswald, Germany

10 Freie Universitat Berlin, Berlin, Germany

11 Smithsonian Tropical Research Institute, Balboa, Ancón, Panama

12 Laboratorio de Bioconservación y Manejo, Posgrado en Ciencias Quimicobiológicas, Departamento de Zoología, Escuela Nacional de Ciencias Biológicas, Instituto Politécnico Nacional, Mexico City, Mexico

13 University of Toronto Mississauga, Mississauga, Canada 
As a first step toward this approach, we used social network analysis on long-term individual records and estimated relatedness using genetic markers for nine species of bats. We confirmed nonrandom emergent social structure in all species. Kinship was predictive of social association among individuals of the same sex in a few species, but largely independent of the occurrence of complex behaviors, such as dominance among males or cooperation among females. Complex social behavior in bats appears to require frequent interactions among a small number of individuals that roost together for multiple years.

Keywords Social networks $\cdot$ Kinship $\cdot$ Modularity $\cdot$ Fission-fusion $\cdot$ Cooperation

\section{Introduction}

Social complexity is often associated with cooperative breeding, especially among insects and birds (Avilés and Harwood 2012; Kappeler 2019, topical collection on Social complexity). Cooperative breeding also occurs in a few mammal species, e.g., some mole rats (Jarvis 1981; Bennett et al. 1996), mongooses (Creel and Creel 1991; Bell et al. 2012, 2014), and canids (Creel et al. 1997; Moehlman and Hofer 1997). In each of these cases, some individuals forego reproduction and provide assistance to closely related reproductives in a group (Clutton-Brock et al. 2001, 2010). Multiple close kin are present because they are born together in a litter from a single-mated female and then remain in an extended family group (Lukas and Clutton-Brock 2012). Cooperative breeding has not been reported in monotocous species, such as most cetaceans, elephants, and primates, despite their frequent inclusion in discussions of social complexity (e.g., Connor et al. 1998; Payne 2003; MacKinnon and Fuentes 2011). In contrast, these species are more likely to exhibit less costly social behaviors, such as alloparental care (Lee 1987; Packer et al. 1992; Roulin 2002; MacLeod and Lukas 2014), information exchange (McComb et al. 2001; Brent et al. 2015), or more complex interactions, such as alliance forming (Seyfarth and Cheney 1984; Connor et al. 1992; Chapais 1995; Silk et al. 2004; Wiszniewski et al. 2012). These interactions sometimes, but not always, involve related individuals (Moller et al. 2001; Parsons et al. 2003; Schino and Aureli 2010) and can have fitness benefits (Silk 2007). Thus, the extent to which social complexity requires cooperative breeding depends on how social complexity is defined. When the definition focuses on the number of differentiated relationships (sensu Freeberg et al. 2012; Bergman and Beehner 2015), the degree to which interactions involve close relatives is an open question.

A first step in assessing the complexity of a social system (sensu Kappeler 2019, topical collection on Social complexity) is to test if patterns of association between individuals occur at random. The extent to which individuals preferentially associate with others over extended periods of time, especially when moving between many different sites (see He et al. 2019, topical collection on Social complexity), provides an indication of the opportunity for repeated and possibly complex interactions. If nonrandom associations exist, then a second step is to test for a correlation between association and relatedness, which could arise simply as a byproduct of sexbiased natal philopatry or as a result of individuals preferentially associating with kin. Where it is possible to observe individuals interacting repeatedly in multiple contexts, the number and type of differentiated social relationships can provide information on additional dimensions of social complexity (Bergman and Beehner 2015; Kappeler 2019, topical collection on Social complexity).

Bats provide an interesting group in which to examine kinship, association, and social complexity because they exhibit diverse social systems, from species that roost solitarily to those that form small groups or large colonies (Bradbury 1977; McCracken and Wilkinson 2000; Kerth 2008). Many bats also live a long time, with longevities of multiple species known to exceed 30 years (Wilkinson and South 2002). Long lifespan enables individuals to interact repeatedly in ways that facilitate cooperation. Examples of cooperative behaviors among bats include information exchange in Spix's diskwinged bats, Thyroptera tricolor (Chaverri et al. 2010, 2013), Watson's fruit-eating bat, Dermanura watsoni (Gillam et al. 2013), Honduran white bats, Ectophylla alba (Gillam et al. 2013), Bechstein's bats, Myotis bechsteinii (Kerth and Reckardt 2003), evening bats, Nycticeius humeralis (Wilkinson 1992b), and greater spear-nosed bats, Phyllostomus hastatus (Wilkinson and Boughman 1998); huddling for warmth in pallid bats, Antrozous pallidus (Trune and Slobodchikoff 1976) and M. bechsteinii (Pretzlaff et al. 2010); social grooming in vampire bats, Desmodus rotundus (Wilkinson 1986; Carter and Leffer 2015); communal nursing in $N$. humeralis (Wilkinson 1992a), pup guarding in P. hastatus (Bohn et al. 2009); and food sharing in D. rotundus (Wilkinson 1984; Carter and Wilkinson 2013b). While kinship has been implicated in some of these behaviors, it appears to be unimportant in others (Wilkinson et al. 2016). This should not be surprising given that bat social structures and life histories more closely resemble those of primates and cetaceans than mole rats or mongooses.

Opportunities for adults to interact with relatives depend on patterns of reproduction and dispersal. Female bats typically give birth to one or occasionally two pups each year (Racey and Entwhistle 2000) and survival to age of first reproduction tends to be low (e.g., Tuttle and Stevenson 1982; Storz 2000), which should serve to lower the likelihood of interacting with 
relatives as adults. Offspring of one or both sexes typically disperse in the first year, presumably to avoid inbreeding (Clutton-Brock and Lukas 2012). All possible sex-biased patterns of dispersal occur in bats. As in most mammals (Greenwood 1980; Clutton-Brock and Lukas 2012), female philopatry with male dispersal away from the birth site is common in bats (Castella et al. 2001; Chen et al. 2008; Moussy et al. 2013). As a consequence, one or more matrilines, each with some close female relatives, can be present in a mixed-sex colony in some tropical species, such as D. rotundus (Wilkinson 1985b), as well as in female maternity colonies of many temperate species, e.g., pallid bats, A. pallidus (Arnold and Wilkinson 2015), northern longeared bats, M. septentrionalis (Patriquin et al. 2013), and N. humeralis (Wilkinson 1992a). However, average relatedness among females in a colony is often very low, e.g., big brown bats, Eptesicus fuscus (Metheny et al. 2007), greater horseshoe bats, Rhinolophus ferrumequinum (Rossiter et al. 2002), and M. bechsteinii (Kerth et al. 2002), and so interactions among relatives require kin-biased associations. Male philopatry with female dispersal also occurs in some species, e.g., greater sac-winged bats, Saccopteryx bilineata (Bradbury and Vehrencamp 1976) and proboscis bats, Rhynchonycteris naso (Nagy et al. 2013), resulting in associations among related adult males. In at least one species, T. tricolor, neither sex disperses from their natal groups, and mating occurs between groups, resulting in closely related males and females roosting together (Chaverri and Kunz 2011; Buchalski et al. 2014). Finally, dispersal of both sexes has been reported in several species, e.g., P. hastatus (McCracken and Bradbury 1981), Lophostoma silvicola (Dechmann et al. 2007), Cynopterus sphinx (Storz 2000; Storz et al. 2001b), and Molossus molossus (Gager et al. 2016), where a single male defends a group of unrelated females for periods that exceed the time to sexual maturity. In these species, adult relatedness is near zero (McCracken 1987; Storz et al. 2001a).

While some bat species form large colonies every year at the same traditional sites, such as particular caves, buildings or trees, in many cavity or crevice roosting species, individuals gather together during the day in small groups, but frequently change roosting sites and partners (Lewis 1995). Careful monitoring of marked individuals over time has, nevertheless, revealed the presence of social units defined by repeated roosting associations in, for example, Chalinolobus gouldii (Godinho et al. 2015), D. rotundus (Wilkinson 1985a), E. fuscus (Metheny et al. 2007), Myotis bechsteinii (Kerth and König 1999; Kerth et al. 2011), M. daubentonii (August et al. 2014), M. septentrionalis (Patriquin et al. 2010), and Nyctalus lasiopterus (Fortuna et al. 2009). Interestingly, M. nattereri forms social units in England (August et al. 2014) but not in Germany (Zeus et al. 2018). Thus, the social structure of many cavity roosting bats is complex and resembles other fission-fusion animal societies (Aureli et al. 2008).
As in African elephant, Loxodonta africana (Archie et al. 2006), giraffe, Giraffa camelopardalis (Carter et al. 2013), and wild boar, Sus scrofa (Podgorski et al. 2014), some, but not all, members of bat social units are related (Wilkinson 1985b; Kerth et al. 2002, 2011; Metheny et al. 2007; Patriquin et al. 2013; Zeus et al. 2018). These observations suggest that individuals identify members of their social unit using some type of cue or signal that is not strictly associated with kinship. For example, some species produce particular social calls with distinctive features that permit discrimination among individuals, such as T. tricolor (Gillam and Chaverri 2012), D. watsoni, E. alba (Gillam et al. 2013), A. pallidus (Arnold and Wilkinson 2011), and D. rotundus (Carter et al. 2012; Carter and Wilkinson 2016), or among groups in P. hastatus (Boughman 1997; Boughman and Wilkinson 1998) and S. bilineata (Knörnschild et al. 2012). In other species, olfactory cues likely serve similar functions, such as in the common pipistrelle, Pipistrellus pipistrellus (Defanis and Jones 1995), the fishing bat, Noctilio leporinus (Brooke and Decker 1996), M. bechsteinii (Safi and Kerth 2003) and several molossid species including Mops condylurus, Chaerophon pumilus, and Tadarida brasiliensis (Bouchard 2001; Englert and Greene 2009). Intriguingly, recent evidence suggests that bats possess place cells in their hippocampus that allow them to track social relationships and proximity to group members (Omer et al. 2018).

Determining if a particular species exhibits nonrandom or kin-biased associations requires quantitative analyses of association and relatedness. Social network analysis (Whitehead 2008; Farine and Whitehead 2015) provides a method for comparing social systems and has been previously applied to bats (Chaverri 2010; Patriquin et al. 2010; Kerth et al. 2011), but no prior study has attempted to compare social networks and relatedness across species. For this reason, we decided to analyze observational and genetic data from long-term studies on nine species from four different families of bats. All nine species roost during the day in distinct sites, such as on or inside furled leaves, trees, caves, or man-made structures, where interactions, such as allogrooming, allofeeding, information transfer and mutual warming, would be restricted to individuals sharing the same roosting site. Consequently, observations of uniquely marked individuals within a roosting site on a given day provide consistency in how data are collected, making them ideal for comparative network analysis (Farine and Whitehead 2015). Similarly, standard nondestructive tissue sampling (Worthington-Wilmer and Barratt 1996) provides comparable genetic data for estimating relatedness across datasets (Wang 2011, 2017).

In this study, we used estimates of association and relatedness to answer three questions. First, do males or females form same-sex associations that are more frequent than expected by chance? We focus on same-sex associations in part because only females are present at maternity sites and can therefore be 
compared across all species. To answer this question, we used randomization methods to determine if the observed coefficient of variation for the simple ratio index, i.e., the proportion of observations in which both individuals were seen roosting together, was greater than would be expected if associations occurred at random (Whitehead 2008; Farine 2017). Second, do individuals preferentially associate with same-sex relatives? We addressed this question both by determining if relatedness predicts association among dyads, and by testing if relatedness predicts membership in a social unit or community, as defined by maximum modularity in the social network (Girvan and Newman 2002; Newman 2004, 2006). Finally, given that the species differ in the degree to which individuals use more than one roosting site, we consider if roost switching influences the patterns of relatedness and association among species.

\section{Methods}

\section{Species}

We used original observation and genotype data for the following nine species of bats, Rhynchonycteris naso, Saccopteryx bilineata (family Emballonuridae), Artibeus jamaicensis, Phyllostomus hastatus, Desmodus rotundus (family Phyllostomidae), Thyroptera tricolor (family Thyropteridae), Nycticeius humeralis, Myotis bechsteinii, and $M$. septentrionalis (family Vespertilionidae). In Online Resource 1, we provide additional information on study site number, location, capture, marking, observations, and methods for obtaining tissue samples for each species, and briefly describe methods for scoring genotypes at polymorphic loci. Table S1 in Online Resource 1 also summarizes the amount of observational and genetic data used for each species. In several species, data were only available for females, either because observations were conducted at summer maternity sites where adult males rarely occur ( $N$. humeralis, $M$. bechsteinii, and $M$. septentrionalis) or because comparable data for adult males were not available ( $P$. hastatus). It was also not possible to record data blind because our study involved censuses of marked animals in the field. Below, we summarize how we analyzed these data.

\section{General approach}

For each species, we used observations of uniquely marked adult individuals in a roosting site on a day to calculate the simple ratio index (SRI) for each dyad (following Hoppitt and Farine 2018). If individuals were banded as juveniles, we assumed adult age is not attained until the individual is at least 9 months old. To improve the accuracy of dyadic association estimates, only individuals observed three or more times as adults were included. We tested for evidence of nonrandom preferred associations using permutation tests (Farine 2017) applied to the SRI coefficient of variation for either male-male dyads, female-female dyads, or all dyads. For species with more than 1000 observations across multiple years, we estimated standardized lagged association rates across days to assess temporal effects on associations of each sex (Whitehead 1995). To reduce confounding spatial associations with temporal associations, we estimated associations among dyads over periods of one or more years for species with sufficient data. For those species, we present average values from nonoverlapping 2-year periods for each of the network metrics described below.

We used the SRI to create a weighted nondirectional network for same-sex dyads for each species and sex within each species using Socprog 2.8 (Whitehead 2009). For each sex, we assigned individuals to communities using the Girvan-Newman maximum modularity method (Girvan and Newman 2002; Newman 2004, 2006). For each potential grouping, modularity measures the difference between the ratio of the sum of SRI within a community over the total SRI to the corresponding ratio when individuals are assigned to communities at random. Modularity values above 0.3 are often used as evidence for the presence of communities in the network (Whitehead 2009), but note that simulations suggest this threshold should be 0.5 (Shizuka and Farine 2016).

We next computed several descriptive metrics. First, we calculated the network density, which is the proportion of possible edges observed given the number of individuals in the network. Second, we estimated two individual-based statistics - strength and eigenvector centrality - then computed the average of these statistics for each sex within each species. Strength is the sum of edge weights connected to a node, i.e., the sum of all SRI involving an individual. If individuals in a group are always observed together, then strength would equal group size minus one. Consequently, we used strength/(group size -1$)$ to estimate group stability. Eigenvector centrality is obtained from the eigenvector of the association matrix, and is a commonly used metric to capture the degree to which individuals associate with others who have high versus low associations (Whitehead 2009).

To estimate dyadic relatedness, we used five different methods in Coancestry 1.0.1.8 (Wang 2011) to analyze genotypes from multiple polymorphic loci. We report the Wang (2017) estimator because it is unbiased for small samples, but other estimates gave similar results. We estimated confidence intervals for these estimates using a bootstrap resampling method (Wang 2011). As expected, the error associated with each dyadic estimate of relatedness was inversely related to the amount of genetic information available, i.e., the number of loci and segregating alleles (see Table in Online Resource 1). For species with 
relatively few segregating alleles, the estimate for any given dyad was poor. However, even for species with fewer than 20 segregating alleles, confidence intervals around estimates for the average relatedness in a community were sufficiently small to be informative with regard to predicting community membership.

We then determined if relatedness predicts association using two methods: (1) a linear regression quadratic assignment procedure (QAP) via the asnipe R package (Farine 2013) to test whether pairwise relatedness predicts dyadic association, and (2) a logistic regression QAP using the netlogit function via the sna $\mathrm{R}$ package to test whether pairwise relatedness predicts the probability that both bats in a given dyad are classfied as members of the same versus different communities. To enable comparison across all nine species and reduce potential differences caused by seasonality or mating systems, we report results for same-sex dyads. To ensure that relatedness estimates were not strongly influenced by sampling effort, we first extracted the residuals from regressing the relatednessassociation beta coefficient on the sample size of bats for all datasets, and then predicted these residuals using number of observations per bat as a proxy for sampling effort. In both cases, the slope estimate was negative and did not significantly differ from zero; thus, relatedness effects were not driven by sampling effort.

To assess the potential effect of roost switching behavior on kinship structure across species, we tested if the relatedness effect estimates (i.e., regression coefficients) were predicted by the relative number of roosting sites used per bat. We calculated the relative number of roosts used for each sex of each species as the number of roosts visited by each bat divided by the number of total roost observations.

\section{Results}

\section{Nonrandom, modular associations by sex}

Analysis of the association patterns reveals strong evidence for nonrandom associations in most sex-species combinations, i.e., the coefficient of variation $(\mathrm{CV})$ for the simple ratio index (SRI) for same-sex pairs is greater than expected from random associations (Table 1). The only exceptions to this pattern are female $N$. humeralis, which were observed at a single site, and female A. jamaicensis, which were observed in 20 sites in two caves. In addition, modularity was greater than 0.3 for all sexspecies categories except for female A. jamaicensis, female M. septentrionalis, and female $M$. bechsteinii. Network diagrams for those species (Online Resource 2) provide evidence for some consistent clusters of individuals, but also considerable associations among females across the broader

Table 1 Sex-specific association and network metrics by species. SRI, simple ratio index; CV, coefficient of variation

\begin{tabular}{|c|c|c|c|c|c|c|c|c|c|c|c|}
\hline Species & Sex & Adults & SRI & $\mathrm{CV}$ (SRI) & Density (\%) & Strength & Modularity & Communities & Cm size & Stability & $\begin{array}{l}\text { Roosts/ } \\
\text { bat }\end{array}$ \\
\hline \multirow[t]{2}{*}{ R. naso } & $\mathrm{F}$ & 45 & 0.167 & $1.85^{* * *}$ & 30.7 & 4.92 & 0.49 & 3.0 & 10.2 & 0.54 & 1.0 \\
\hline & M & 45 & 0.126 & $2.03 * * *$ & 29.0 & 3.34 & 0.57 & 4.0 & 6.9 & 0.57 & 1.1 \\
\hline \multirow[t]{2}{*}{ S. bilineata } & $\mathrm{F}$ & 65 & 0.112 & $2.31 * * *$ & 24.2 & 2.89 & 0.67 & 4.0 & 7.3 & 0.46 & 1.1 \\
\hline & M & 41 & 0.107 & $2.39 * * *$ & 20.4 & 1.55 & 0.43 & 6.0 & 2.8 & 0.89 & 1.0 \\
\hline \multirow[t]{2}{*}{ T. tricolor } & $\mathrm{F}$ & 18 & 0.099 & $2.33 * * *$ & 23.5 & 1.68 & 0.52 & 6.0 & 3.0 & 0.84 & 11.6 \\
\hline & M & 15 & 0.136 & $2.23 * * *$ & 24.8 & 1.90 & 0.66 & 4.0 & 3.8 & 0.69 & 13.0 \\
\hline \multirow[t]{2}{*}{ A. jamaicensis } & $\mathrm{F}$ & 63 & 0.028 & 1.69 & 31.8 & 1.39 & 0.25 & 5.0 & 10.1 & 0.15 & 4.9 \\
\hline & M & 16 & 0.023 & $2.78 *$ & 21.0 & 0.30 & 0.45 & 5.0 & 3.0 & 0.15 & 2.0 \\
\hline P. hastatus & $\mathrm{F}$ & 97 & 0.059 & $2.69 *$ & 21.1 & 5.64 & 0.67 & 7.0 & 13.9 & 0.44 & 1.8 \\
\hline \multirow[t]{2}{*}{ D. rotundus } & $\mathrm{F}$ & 64 & 0.061 & $1.87 * * *$ & 45.0 & 3.82 & 0.43 & 3.0 & 21.3 & 0.19 & 3.1 \\
\hline & M & 62 & 0.021 & $3.50 * *$ & 22.7 & 1.25 & 0.55 & 6.0 & 10.3 & 0.13 & 2.8 \\
\hline N. humeralis & $\mathrm{F}$ & 97 & 0.145 & 1.07 & 73.0 & 13.94 & 0.32 & 2.0 & 48.5 & 0.29 & 1.0 \\
\hline M. septentrionalis & $\mathrm{F}$ & 63 & 0.057 & $1.86^{* * *}$ & 38.7 & 3.54 & 0.20 & 8.0 & 7.9 & 0.52 & 6.7 \\
\hline M. bechsteini & $\mathrm{F}$ & 61 & 0.262 & $0.77 *$ & 90.9 & 11.59 & 0.23 & 2.5 & 19.2 & 0.64 & 31.6 \\
\hline
\end{tabular}

$* p<0.05, * * p<0.01, * * * p<0.001$, randomization 
population. Together, these data provide strong evidence for nonrandom social structure created by the presence of detectable communities in most species.

Interestingly, even though the number of roosting sites varied from 1 to 184 (see Online Resource 1), the number of communities ranged only from 2 to 8 . Community size estimates varied from seven male and female T. tricolor to over 45 female $N$. humeralis (Table 1). Even though observations of $N$. humeralis were limited to a single roost, two communities were detected (see Online Resource 2) because sets of individuals were occasionally absent simultaneously from the primary roost, presumably because they spent time in one or more secondary roosts. Remarkably, the network for $N$. humeralis most closely resembles the network for M. bechsteinii (see Online Resource 2) even though females in the latter species moved among 78 different roost boxes. In contrast, the number of communities for males and females of the two emballonurid species, $R$. naso and $S$. bilineata, were the same as the number of roosting sites observed in a given year, because the bats rarely moved between roosting sites during the study (Table 1). Examination of the network for $R$. naso clearly shows that the communities are defined by the roosting sites (Fig. 1a).

For those species where both males and females were observed, comparison of network densities showed that femalefemale associations were more common than male-male associations in the two phyllostomid bats, D. rotundus and A. jamaicensis. In contrast, network densities for males and females of the two emballonurids and T. tricolor (Table 1) were nearly identical. Female-female communities were larger than male-male communities for most species except T. tricolor. In this species, communities typically contained nearly equal numbers of individuals of both sexes (Table 1). T. tricolor also had the most unique network structure in that individuals of both sexes rarely associated with same-sex individuals from other communities (Fig. 1b). By contrast, despite having well-defined communities, female vampire bats frequently roosted with females from other communities (Fig. 1c). Male vampire bats were observed in a fewer number of roosts, so they had a lower network density and formed a greater number of communities (Fig. 1d).

Group stability, as measured by the degree to which average node strength equals group size minus one, varied from 0.13 in male D. rotundus to 0.89 in male $S$. bilineata (Table 2). Group stability was also typically greater in female-female networks than male-male networks, except in the two emballonurid species where it was higher in males and A. jamaicensis where it was similar in males and females.

\section{Sex differences in temporal associations}

In the four species where sufficient data were available, we estimated standardized time-lagged same-sex associations for each sex. This metric estimates the probability that if two individuals are associated at any time, then, after the specified lag, the second individual is a chosen associate of the first. In
Fig. 1 Network diagrams displaying community identity for a Rhynchoyncteris naso from 2013 to 2014 at three sites, b Thyroptera tricolor from 78 sites, c Desmodus rotundus females, and $\mathbf{d}$ males from 15 hollow trees. Line width indicates strength of association. In $\mathbf{a}$ and $\mathbf{b}$, node color denotes sex (pink, female; blue, male) while in $\mathbf{c}$ and $\mathbf{d}$, node color denotes community identity. See Online Resource 2 for network diagrams of the other species
A. R. naso

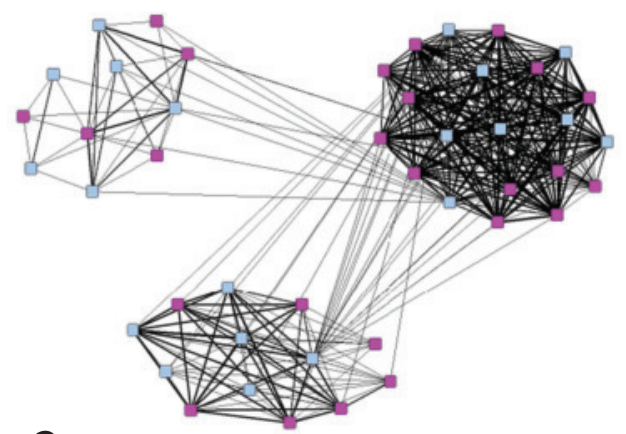

C. D. rotundus females

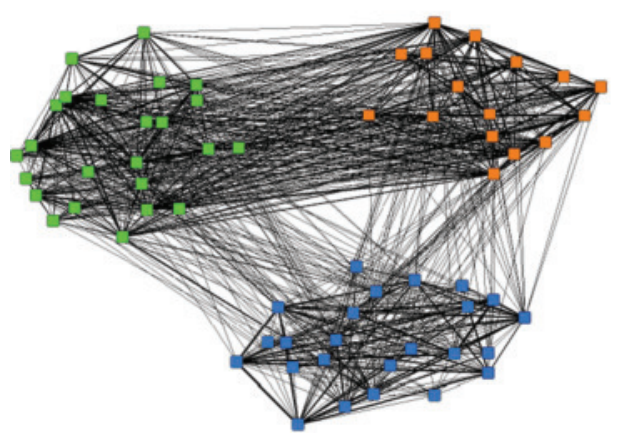

B. T. tricolor

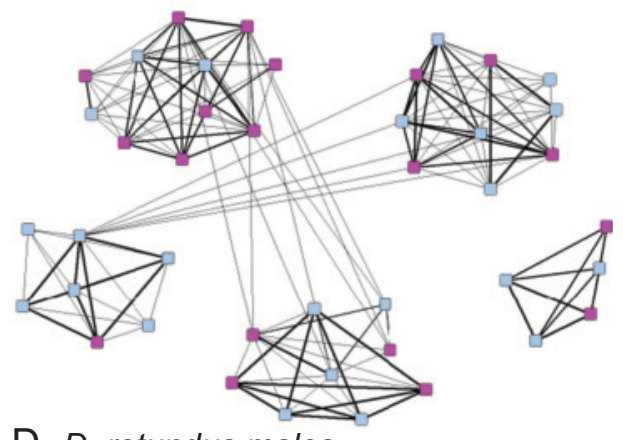

D. D. rotundus males

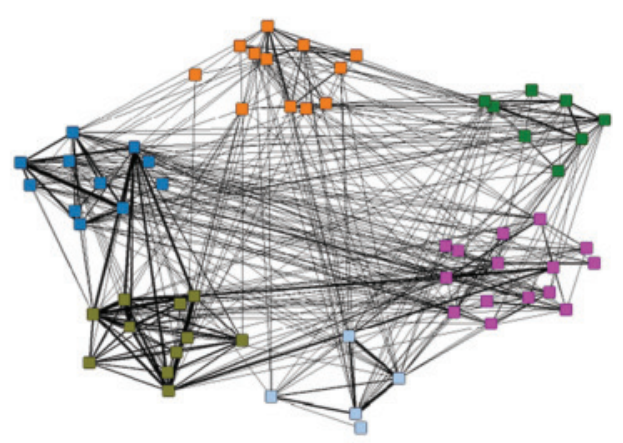


Table 2 Sex bias in dispersal pattern (F, female; M, male), relatedness ( $r$ ) vs. association relationship (SRI), and types of behavioral interactions for each species

\begin{tabular}{|c|c|c|c|c|c|c|c|}
\hline Species & $\begin{array}{l}\text { Dispersing } \\
\text { sex }\end{array}$ & $\begin{array}{l}r \text { vs. } \\
\text { SRI }\end{array}$ & $\begin{array}{l}\text { Dominance } \\
\text { hierarchy }\end{array}$ & $\begin{array}{l}\text { Information } \\
\text { exchange }\end{array}$ & $\begin{array}{l}\text { Alloparental } \\
\text { care }\end{array}$ & $\begin{array}{l}\text { Social } \\
\text { grooming }\end{array}$ & $\begin{array}{l}\text { Food } \\
\text { sharing }\end{array}$ \\
\hline R. naso & $\mathrm{F}$ & M & M & & & & \\
\hline S. bilineata & $\mathrm{F}$ & ns & M & & & & \\
\hline T. tricolor & Neither* & $\mathrm{M}, \mathrm{F}$ & $?$ & $\mathrm{M}, \mathrm{F}$ & & & \\
\hline A. jamaicensis & $?$ & M & M & & & $\mathrm{F}>\mathrm{M}$ & \\
\hline P. hastatus & $\mathrm{M}, \mathrm{F}$ & ns & M & $\mathrm{F}$ & $\mathrm{F}$ & & \\
\hline D. rotundus & M & $\mathrm{F}$ & M & $\mathrm{F}$ & $\mathrm{F}$ & $\mathrm{F}>\mathrm{M}$ & $\mathrm{F}$ \\
\hline N. humeralis & M & $\mathrm{ns}$ & & $\mathrm{F}$ & $\mathrm{F}$ & & \\
\hline M. septentrionalis & M & ns & & $\mathrm{F}$ & & & \\
\hline M. bechsteinii & M & $\mathrm{F}$ & & $\mathrm{F}$ & & F & \\
\hline
\end{tabular}

*Dispersal of either sex occurs infrequently

? Undescribed

all cases where data were available for both sexes, standardized lagged association rates among females remained above null expectations for longer periods of time than standardized lagged association rates among males (Fig. 2). For $R$. naso males, time lags greater than 3 years had standardized lagged association rates comparable to random expectation, while female standardized lagged association rates remained above random levels after 1200 days. In S. bilineata, time lags of 600 days resulted in standardized lagged association rates equal to random expectation levels for males but not for females. Similarly, in D. rotundus, male standardized lagged association rates reached random expectation by 600 days, at which point female standardized lagged association rates were still well above null expectations. For comparison, standardized lagged association rates for female $M$. bechsteinii reached null expectation after 3 years. Thus, in all four species, interactions among females appear to be maintained for much longer periods of time than among males.

\section{Relatedness and association}

For same-sex dyads, relatedness predicted association in female-female dyads in D. rotundus and $M$. bechsteinii, among male-male dyads in A. jamaicensis, and both female-female and male-male dyads in T. tricolor (Fig. 3). In addition, examination of the T. tricolor data reveals that some males that exhibit high levels of association were unrelated while unrelated females rarely exhibited high levels of assocation (Fig. 4).

Given that the relationships illustrated in Fig. 3 used all possible same-sex dyads, we wanted to determine if relatedness could be used to assign individuals to the communities defined by maximizing modularity. This analysis produced results similar to the matrix regression approach (Fig. 5a), except that this method detected an effect of relatedness on the probability of male-male $R$. naso dyads being in the same community. In addition, because this analysis provides estimates for both the mean of and variation in withincommunity relatedness, it is possible to compare average within-community relatedness across species. Most notably, the within-community relatedness in T. tricolor is more than twice as high as any other species (Fig. 5b).

To determine if patterns of kin-based association could be influenced by movement among roosts, we first calculated the relative rate of roost switching as the number of roosts used by each bat (Table 1) divided by the number of observed roost sites visited by any bat to control for sampling effort. We then tested if the relative rate of roost switching predicted the relationship between relatedness and association. We found that the strength of the relationship between relatedness and association, as measured by either the QAP regression coefficient $(t=8.94, p<0.0001)$ or the logistic regression coefficient $(t=7.22, p<0.0001)$, was greater when bats visited more roosts (Fig. 6).

\section{Discussion}

Social network analysis has been widely used to quantify relationships among individuals within a species (Whitehead 2008). Rarely, however, has it been used to compare social relationships among species (but see Kudo and Dunbar 2001; Pasquaretta et al. 2014) because methods often differ among investigators and by species. Because many echolocating bats spend the day in roosting sites, observations of bats roosting together on a day provide a common metric for measuring associations. In this study, we used such data, in conjunction with genetic data, to determine if relatedness influences patterns of association in nine species of bats.

\section{Patterns of association and roosting behavior}

Many species of bats change roosts often, sometimes on a daily basis (Lewis 1995). In other species, individuals 
Fig. 2 Standardized lagged association rates plotted against time in days for female and male R. naso, S. bilineata, and D. rotundus. Standard errors are estimated by jackknifing. Red lines in each plot indicate standardized null association rates

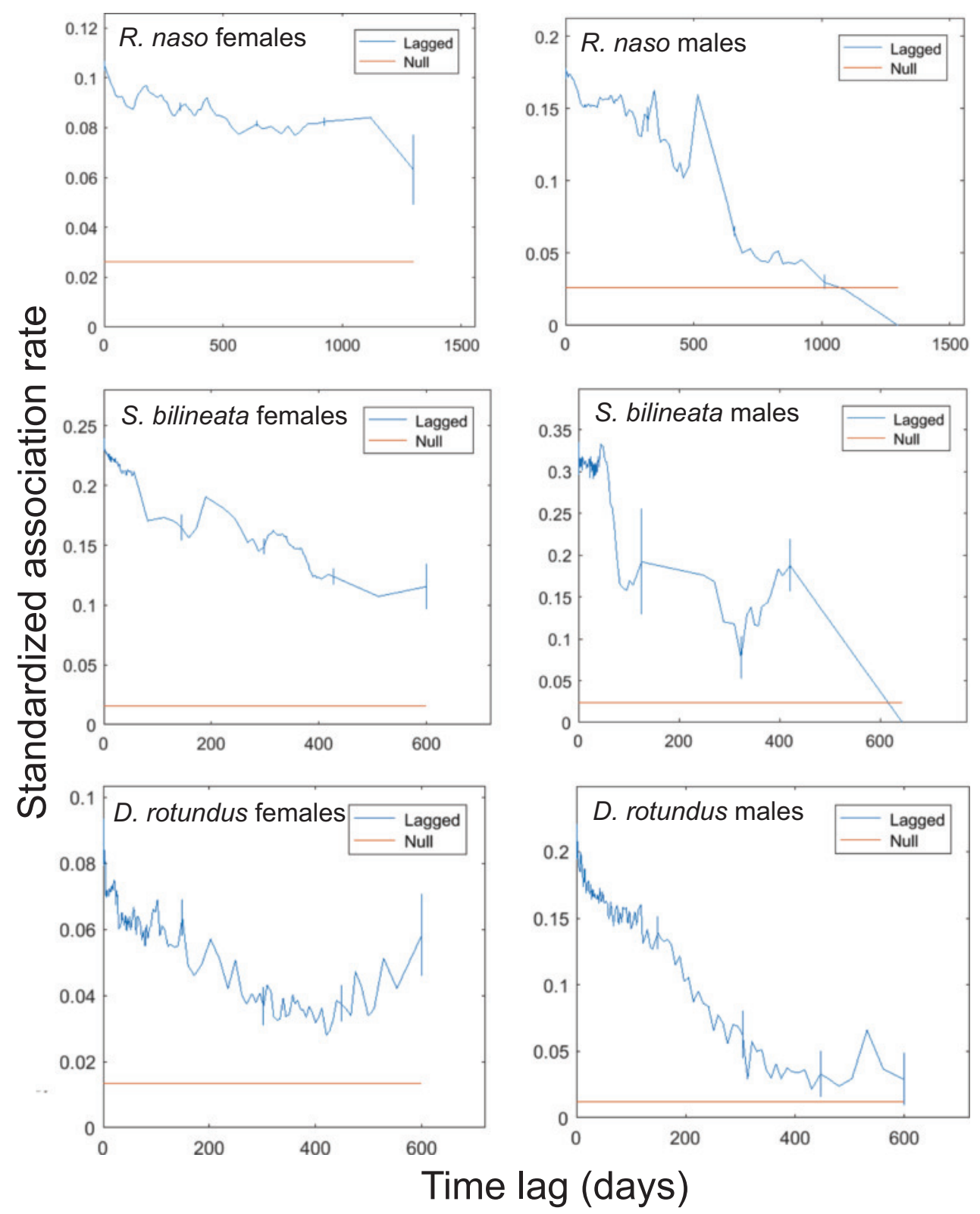

consistently return to traditional roosting sites over many days or even years. In this study, we have examples of both types of movement patterns. In the two emballonurid species, $R$. naso and S. bilineata, the number of communities (Table 2) is close to the number of roosting sites (Table 1) and individual bats rarely moved between sites. However, in both species, more communities are predicted for males than for females. Males of these species also exhibit faster decay in lagged associations than females (Fig. 2). Examination of the composition of the predicted male communities reveals that the presence of more communities than sites is a consequence of low associations across years among males at some sites. When data for a single year are analyzed (data not shown), the number of communities matches the number of sites for males of both emballonurid bat species. The two emballonurid species can occupy roost sites for many years. Consequently, it is possible that their social associations could result from passive attraction to a favorite or familiar roosting site rather than to preferred individuals. For species that do not switch roosts often, it is difficult to disentangle preferred sites and preferred conspecifics because individuals might prefer roosting sites because of the particular conspecifics located there.

In $N$. humeralis, modularity analysis revealed two communities, but both were detected in a single common roost site. In this case, some bats used at least one other unobserved roost during the observation period. Additional observations of radio-tagged $N$. humeralis indicate that some individuals do switch roosts together and occupy hollow 


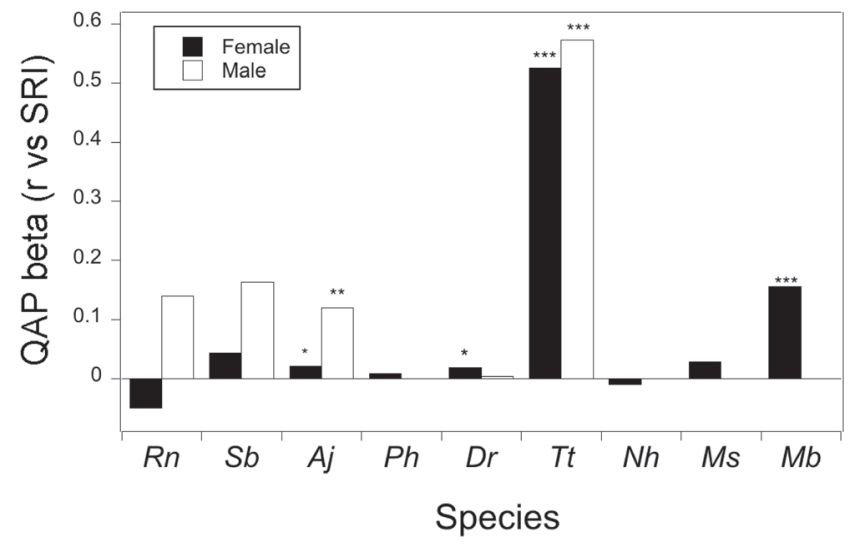

Fig. 3 Regression slopes (beta) obtained from a quadratic assignment procedure (QAP) for the relationship between association, as measured by the simple ratio index (SRI), plotted against relatedess $(r)$, using the Wang (2017) estimator, for males and females of each species. For species names, see Table S1. Significance is indicated as $* p<0.05$, $* * p<0.01, * * * p<0.001$

trees as well as attics (Wilkinson 1992b), providing additional evidence that associations in this species are not due solely to occupancy of a single roost site.

Even though two of the phyllostomid species are similar in that females form groups year round in cave ceiling depressions, they differ with respect to group stability. In A. jamaicensis, females show little fidelity to a site and frequently switch groups, i.e., they had low modularity and low stability (Table 1). In contrast, P. hastatus females show much higher modularity and fairly high stability. Previous studies reported that female P. hastatus remain together for multiple years independent of the identity of the harem male or the group's physical location within the cave (McCracken and Bradbury 1981).
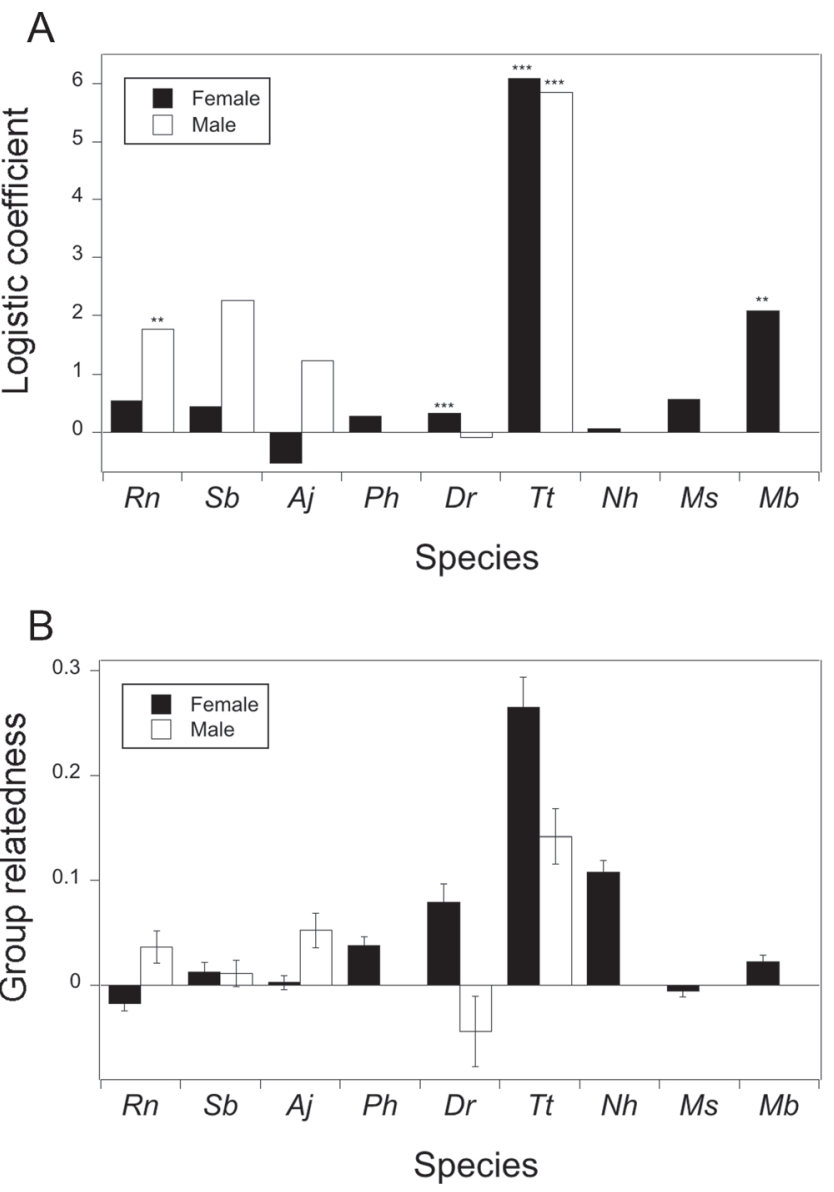

Fig. 5 a Logistic regression coefficients for assignment of individuals to community as predicted by maximizing modularity. For species names, see Table S1. Significance is indicated as $* p<0.05, * * p<0.01$, $* * * p<0.001$. b Average within-community relatedness for each sex and species. Standard errors obtained by bootstrapping

Our data are largely consistent with this description with the exception of occasional movement between groups
Fig. 4 Relationship between simple ratio index association and relatedness, using the Wang (2017) estimator, for a male and b female Thyroptera tricolor. Quadratic assignment procedure regression lines shown with $95 \%$ confidence limits

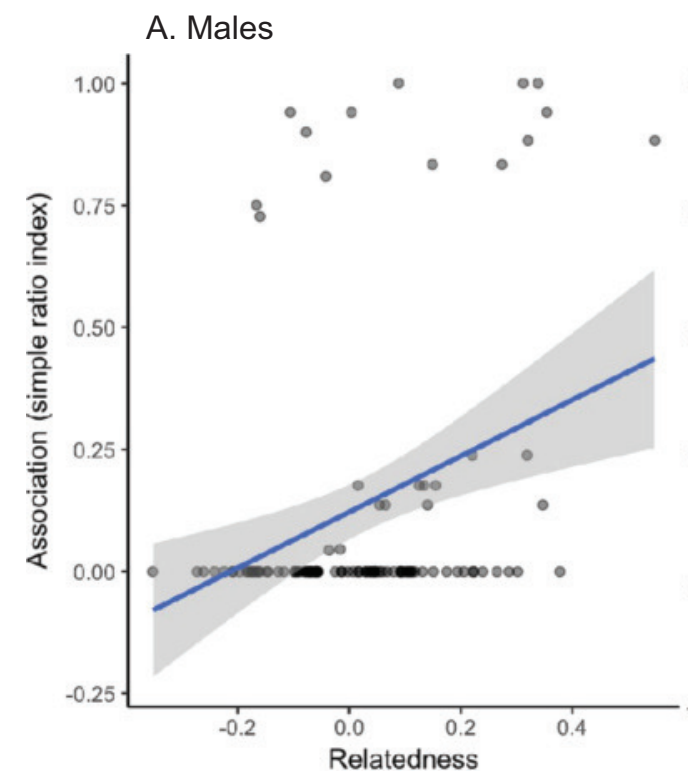

B. Females 


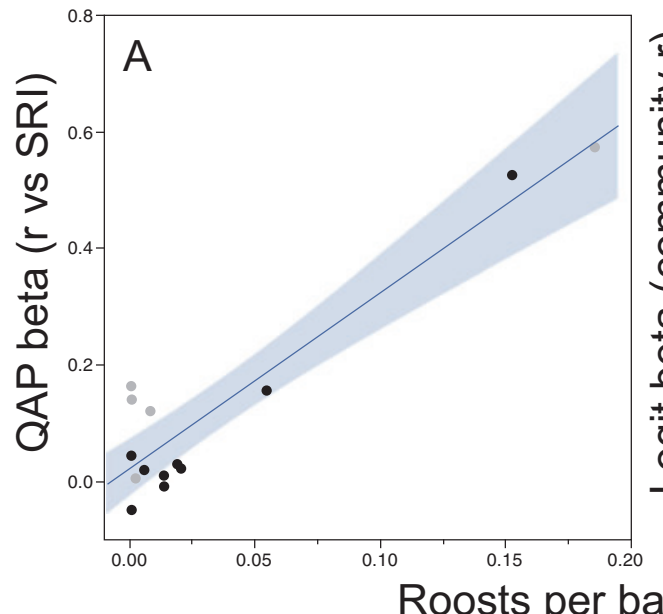

Roosts per bat/roosts visited
Fig. 6 Amount of roost switching, as measured by the number of roosts occupied per bat divided by number of roost observations plotted against a the regression coefficient obtained from a quadratic assignment procedure (QAP) for the relationship between association (SRI) and

perhaps as a consequence of the greater number of groups ( 20 vs. 3 ) in the cave than in the earlier study at the same site (McCracken and Bradbury 1981).

In all species that roost in hollow tree cavities, community members use multiple roosts, so nonrandom associations are evidence of social preferences rather than attraction to a mutually preferred site. In D. rotundus, females formed larger samesex communities and moved between more roosting sites than males. In the two tree-roosting Myotis species, females always roosted with others, but the composition of the roosting aggregation often changed. These fission-fusion dynamics, also observed in primates and other species (Aureli et al. 2008), appear to be common in cavity-dwelling bat species (Metheny et al. 2007; August et al. 2014; Garg et al. 2018; Zeus et al. 2018).

Table 1 shows that nearly every species forms nonrandom associations in which communities can be identified even though roost sites could typically accomodate a larger number of individuals than are found (although it might be difficult for many more $T$. tricolor individuals to roost in a single rolled leaf). Communities are not fully segregated. In D. rotundus, M. septentrionalis, and $M$. bechsteinii, for example, members of two communities also roosted together. These observations are consistent with a hierarchical social organization, such as has been described for some primates (e.g., Dunbar 1983) and African elephants (Wittemyer et al. 2009), that is independent of spatial drivers (see Farine and Sheldon 2016; He et al. 2019, topical collection on Social complexity).

Larger groups can facilitate exchange of information, such as the location of difficult-to-discover prey patches (Aplin et al. 2012), but also transmission of pathogens among more individuals (Craft 2015; Sah et al. 2017). These conflicting pressures might be acute for vampire bats, which sometimes take turns feeding from the same

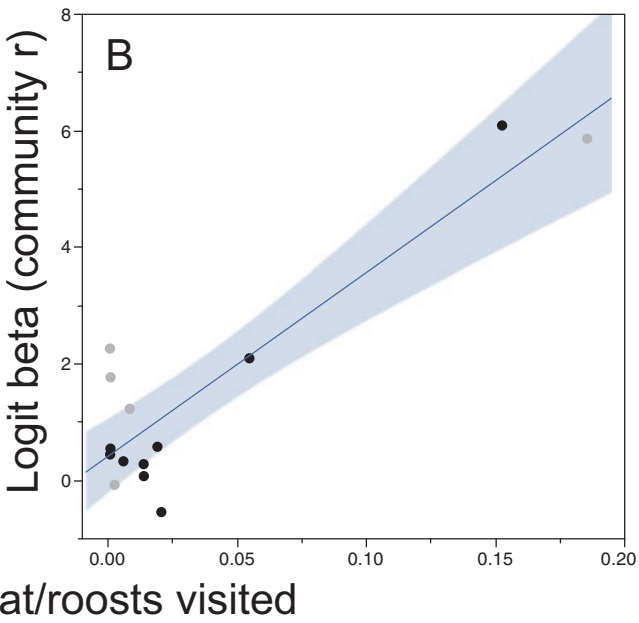

relatedness $(r)$ and $\mathbf{b}$ the logistic regression coefficient for assignment of individual to community as defined by maximizing modularity on the basis of relatedness. Females are indicated by black points, males by gray points

difficult-to-locate prey animal (Wilkinson 1985a), but are also at risk of rabies transmission (Blackwood et al. 2013; Johnson et al. 2014). The potential costs associated with a larger and more highly connected network could explain why network densities were below $50 \%$ for every species except $N$. humeralis and $M$. bechsteinii. As a consequence, the mean association index was also low due to many dyads rarely being found together. Whether larger aggregations represent passive occupancy of a convenient roost site or whether they enable social interactions with fitness consequences is worthy of further study.

Formation of a community independent of a roosting site requires that group members find and recognize each other at night. Playback studies have shown that social calls emitted by $M$. bechsteinii and $M$. nattereri attract conspecifics to roost sites (Schöner et al. 2010). Simple attraction to conspecifics could lead to group formation, but not necessarily stable associations, which require individual or group-level discrimination. Several species of bats give or exchange vocalizations prior to joining a roosting group and these vocalizations often are individually distinctive (Arnold and Wilkinson 2011; Carter et al. 2012; Gillam and Chaverri 2012; Gillam et al. 2013). This type of recognition system is likely to be a prerequisite for more complex behaviors.

\section{Patterns of association and relatedness}

We found that relatedness predicts same-sex association largely in accordance with patterns expected from interspecific variation in dispersal (Table 2). In R. naso, S. bilineata, and A. jamaicensis, where females are more likely to disperse (Ortega et al. 2003; Nagy et al. 2012, 2013), relatedness is more likely to predict group assignment in males than females. 
In contrast, in the species where males disperse, which includes the three temperate vespertilionid species and the vampire bat, $D$. rotundus, females are more likely to form communities with female relatives. In species where both sexes disperse, such as $P$. hastatus, relatedness does not influence association. Finally, in the disk-winged bats, T. tricolor, relatedness is a strong predictor of association in both males and in females. These bats are perhaps most similar to killer whales, Orcinus orca (Parsons et al. 2009) in that females and males remain with their mother, but mating occurs between groups (Chaverri and Kunz 2011). Both sexes also show high levels of group stability (cf. Table 1) and have higher average levels of relatedness than any other species (Fig. 5b). Group stability is maintained by individual-specific vocalizations that are used to reunite individuals in a new roost every day (Chaverri et al. 2010, 2013; Gillam and Chaverri 2012; Chaverri and Gillam 2015).

We did not detect any pattern between the strength of the relationship between association and relatedness and any feature of the social network. Instead, this relationship appears to be positively related to the degree of roost switching (cf. Fig. 6). This result suggests that same-sex communities are more likely to contain relatives in species where individuals frequently switch roosts. This pattern might be due to young of the year following matrilineal relatives after they become volant, and then females continuing to move together in subsequent years. We suspect this pattern will hold for species in which individuals change roost sites frequently and form stable groups. At least one other species, the pallid bat (Antrozous pallidus), is consistent with this prediction. In many parts of its range, female pallid bats roost in rock crevices during the day and often switch roosts daily (Lewis 1996). Colonies contain matrilineal relatives as a consequence of natal philopatry (Arnold and Wilkinson 2015) and estimates of relatedness among adult females in those groups are significantly higher than expected if groups formed at random (Arnold 2011). Similar to T. tricolor, pallid bats give contact calls prior to entering a day roost (Arnold and Wilkinson 2011) and acoustic similarity between calls correlates with relatedness (Arnold 2011), suggesting that relatives may find each other using vocalizations. In our study, association predicted relatedness most strongly for female $M$. bechsteinii, female $D$. rotundus, and both sexes of T. tricolor. In contrast, $D$. rotundus males use fewer roost sites than females, form smaller groups, and are not related. Similarly, in $M$. bechsteinii, solitary males move much less among roosts than colony-living females (Kerth and Morf 2004). Conversely, we anticipate that stable groups of unrelated individuals, such as occurs in female $P$. hastatus (McCracken and Bradbury 1981), require a traditional site to form a community. To our knowledge, data are not available to determine if association predicts relatedness for bat species that roost together in large groups and often use multiple sites, such as some flying foxes (Parsons et al. 2011; Roberts et al. 2012). Comparable data for these species would provide a useful comparison.

\section{Social complexity}

Many types of behavioral interactions can impact the fitness of group members and contribute to social complexity (Freeberg et al. 2012; Bergman and Beehner 2015). While detailed observational studies on individually marked animals in multiple contexts are not available for all species included in this study, categorical information exists on the occurrence of behaviors that mediate conflict, i.e., dominance and cooperative behaviors (Table 2). These behaviors vary in the degree to which social cognition is required. For example, in the absence of any morphological correlates, a stable linear dominance hierarchy requires individual recognition and memory of at least recent interactions. Thus, categorizing species by types of behavioral interactions can provide information on an additional dimension of social complexity. Whether relatedness helps to explain any of this variation is an open question.

In several species, dominance relationships have been described among males. For example, in P. hastatus, D. rotundus, S. bilineata, and A. jamaicensis, subordinate males are excluded from roosts with females that are defended by a single dominant male (Bradbury and Vehrencamp 1976; Morrison 1979; McCracken and Bradbury 1981; Wilkinson 1985b; Park 1991; Ortega and Arita 2000; Heckel and von Helversen 2002). Subordinate males in A. jamaicensis are sometimes close relatives of the dominant male (Ortega et al. 2003). Similarly, in $R$. naso, diurnal roosting groups contain multiple males and females, but one or two males in a group exhibit dominance with regard to their nocturnal roosting location and mating (Günther et al. 2016). As in A. jamaicensis, male $R$. naso are often related within a community due to natal philopatry (Nagy et al. 2013). However, the extent to which any of these dominance relationships extend beyond categorization of one dominant vs. multiple subordinates and instead result in a linear hierarchy or an even more complex triadic relationship, such as an alliance, is unclear. Harem males are typically older in P. hastatus, S. bilineata, and D. rotundus, but otherwise morphologically indistinguishable, which suggests that age may be important for attaining dominant status (McCracken and Bradbury 1981; Wilkinson 1985b; Heckel and von Helversen 2002). Subordinate males in these species also often roost in particular locations, which could provide spatial cues for recognition.

In contrast to reported cases of dominance, most of which involve males, several different types of potential cooperative behaviors have been described for female bats (Wilkinson 1987; Kerth 2008; Carter and Wilkinson 2013a). Among the species included in this study, these behaviors occur predominantly among females that are sometimes, but not always, 
related (Table 2). Thus, while natal philopatry can result in related individuals developing associations in bat species that switch roosts frequently, relatedness does not appear to be necessary for cooperation to arise among individuals within communities.

Evidence from at least two species suggests that persistent relationships can be important in more than one social context. Female greater spear-nosed bats, $P$. hastatus, do not roost with relatives (McCracken and Bradbury 1981), but they do use group-specific vocalizations to forage together (Boughman and Wilkinson 1998; Wilkinson and Boughman 1998). They also protect nonoffspring pups in their group from infanticidal females from different groups if pups fall to the cave floor and the mother is absent (Bohn et al. 2009). Thus, females exhibit group-specific interactions in multiple contexts, but it is unclear if their responses depend directly on prior interactions. In common vampire bats, $D$. rotundus, females preferentially regurgitate blood to past roostmates that fail to obtain a blood meal (Wilkinson 1984). When housed together, food sharing is predicted by social grooming and reciprocal food sharing more than by relatedness (Carter and Wilkinson 2013b). Vampire bats also approach playbacks of vocalizations from unrelated food-sharing partners but not nonsharing relatives (Carter and Wilkinson 2016). Such a response minimally requires individual recognition and memory of the prior behavior of others. We suspect that more examples of complex social interactions in bats will be discovered as more detailed social information is collected across multiple contexts. The degree to which these interactions involve related versus unrelated individuals will be interesting to discover.

Acknowledgments We thank B. Negash for assistance in preparing data and H. Whitehead, D. Lukas, P. Kappeler, and two anonymous reviewers, as well as several other participants of the Göttinger Freilandtage, for useful suggestions.

\section{Compliance with ethical standards}

Conflict of interest The authors declare that they have no conflict of interest.

Ethical approval All applicable international, national, and/or institutional guidelines for the care and use of animals were followed.

\section{References}

Aplin LM, Farine DR, Morand-Ferron J, Sheldon BC (2012) Social networks predict patch discovery in a wild population of songbirds. Proc R Soc Lond B 279:4199-4205

Archie EA, Moss CJ, Alberts SC (2006) The ties that bind: genetic relatedness predicts the fission and fusion of social groups in wild African elephants. Proc R Soc Lond B 273:513-522
Arnold BD (2011) Social vocalizations and their implications for group dynamics of pallid bats (Antrozous pallidus). Doctoral dissertation, University of Maryland

Arnold BD, Wilkinson GS (2011) Individual specific contact calls of pallid bats (Antrozous pallidus) attract conspecifics at roosting sites. Behav Ecol Sociobiol 65:1581-1593

Arnold BD, Wilkinson GS (2015) Female natal philopatry and gene flow between divergent clades of pallid bats (Antrozous pallidus). J Mammal 96:531-540

August TA, Nunn MA, Fensome AG, Linton DM, Mathews F (2014) Sympatric woodland Myotis bats form tight-knit social groups with exclusive roost home ranges. PLoS One 9:e112225

Aureli F, Schaffner CM, Boesch C et al (2008) Fission-fusion dynamics: new research frameworks. Curr Anthropol 49:627-654

Avilés L, Harwood G (2012) A quantitative index of sociality and its application to group living spiders and other social organisms. Ethology 118:1219-1229

Bell MBV, Nichols HJ, Gilchrist JS, Cant MA, Hodge SJ (2012) The cost of dominance: suppressing subordinate reproduction affects the reproductive success of dominant female banded mongooses. Proc R Soc Lond B 279:619-624

Bell MBV, Cant MA, Borgeaud C, Thavarajah N, Samson J, CluttonBrock TH (2014) Suppressing subordinate reproduction provides benefits to dominants in cooperative societies of meerkats. Nat Commun 5:4499

Bennett NC, Faulkes CG, Molteno AJ (1996) Reproductive suppression in subordinate, non-breeding female Damaraland mole-rats: two components to a lifetime of socially induced infertility. Proc R Soc Lond B 263:1599-1603

Bergman TJ, Beehner JC (2015) Measuring social complexity. Anim Behav 103:203-209

Blackwood JC, Streicker DG, Altizer S, Rohani P (2013) Resolving the roles of immunity, pathogenesis, and immigration for rabies persistence in vampire bats. Proc Natl Acad Sci U S A 110:20837-20842

Bohn KM, Moss CF, Wilkinson GS (2009) Pup guarding by greater spear-nosed bats. Behav Ecol Sociobiol 63:1693-1703

Bouchard S (2001) Sex discrimination and roostmate recognition by olfactory cues in the African bats, Mops condylurus and Chaerephon pumilus (Chiroptera: Molossidae). J Zool 254:109-117

Boughman JW (1997) Greater spear-nosed bats give group-distinctive calls. Behav Ecol Sociobiol 40:61-70

Boughman JW, Wilkinson GS (1998) Greater spear-nosed bats discriminate group mates by vocalizations. Anim Behav 55:1717-1732

Bradbury JW (1977) Social organization and communication. In: Wimsatt WA (ed) The biology of bats. Academic Press, New York, pp 1-72

Bradbury JW, Vehrencamp SL (1976) Social organization and foraging in emballonurid bats. I. Field studies. Behav Ecol Sociobiol 1:337-381

Brent LJ, Franks DW, Foster EA, Balcomb KC, Cant MA, Croft DP (2015) Ecological knowledge, leadership, and the evolution of menopause in killer whales. Curr Biol 25:746-750

Brooke AP, Decker DM (1996) Lipid compounds in secretions of fishing bat, Noctilio leporinus (Chiroptera: Noctilionidae). J Chem Ecol 22: 1411-1428

Buchalski MR, Chaverri G, Vonhof MJ (2014) When genes move farther than offspring: gene flow by male gamete dispersal in the highly philopatric bat species Thyroptera tricolor. Mol Ecol 23:464-480

Carter G, Leffer L (2015) Social grooming in bats: are vampire bats exceptional? PLoS One 10:e138430

Carter GG, Wilkinson GS (2013a) Cooperation and conflict in the social lives of bats. In: Adams RA, Pedersen SC (eds) Bat evolution, ecology, and conservation. Springer Science Press, New York, pp 225-242

Carter GG, Wilkinson GS (2013b) Food sharing in vampire bats: reciprocal help predicts donations more than relatedness or harassment. Proc R Soc Lond B 280:20122573 
Carter GG, Wilkinson GS (2016) Common vampire bat contact calls attract past food-sharing partners. Anim Behav 116:45-51

Carter GG, Logsdon R, Arnold BD, Menchaca A, Medellin RA (2012) Adult vampire bats produce contact calls when isolated: acoustic variation by species, population, colony, and individual. PLoS One 7:e38791

Carter KD, Brand R, Carter JK, Shorrocks B, Goldizen AW (2013) Social networks, long-term associations and age-related sociability of wild giraffes. Anim Behav 86:901-910

Castella V, Ruedi M, Excoffier L (2001) Contrasted patterns of mitochondrial and nuclear structure among nursery colonies of the bat Myotis myotis. J Evol Biol 14:708-720

Chapais B (1995) Alliances as a means of competition in primates: evolutionary, developmental, and cognitive aspects. Yearb Phys Anthropol 38:115-136

Chaverri G (2010) Comparative social network analysis in a leaf-roosting bat. Behav Ecol Sociobiol 64:1619-1630

Chaverri G, Gillam EH (2015) Repeatability in the contact calling system of Spix's disc-winged bat (Thyroptera tricolor). R Soc Open Sci 2: 140197

Chaverri G, Kunz TH (2011) All-offspring natal philopatry in a neotropical bat. Anim Behav 82:1127-1133

Chaverri G, Gillam EH, Vonhof MJ (2010) Social calls used by a leafroosting bat to signal location. Biol Lett 6:441-444

Chaverri G, Gillam EH, Kunz TH (2013) A call-and-response system facilitates group cohesion among disc-winged bats. Behav Ecol $24: 481-487$

Chen S-F, Jones G, Rossiter SJ (2008) Sex-biased gene flow and colonization in the Formosan lesser horseshoe bat: inference from nuclear and mitochondrial markers. J Zool 274:207-215

Clutton-Brock TH, Lukas D (2012) The evolution of social philopatry and dispersal in female mammals. Mol Ecol 21:472-492

Clutton-Brock TH, Russell AF, Sharpe LL, Brotherton PNM, McIlrath GM, White S, Cameron EZ (2001) Effects of helpers on juvenile development and survival in meerkats. Science 293:2446-2449

Clutton-Brock TH, Hodge SJ, Flower TP, Spong GF, Young AJ (2010) Adaptive suppression of subordinate reproduction in cooperative mammals. Am Nat 176:664-673

Connor RC, Smolker RA, Richards AF (1992) Two levels of alliance formation among male bottle-nosed dolphins (Tursiops sp.). Proc Natl Acad Sci U S A 89:987-990

Connor RC, Mann J, Tyack PL, Whitehead H (1998) Social evolution in toothed whales. Trends Ecol Evol 13:228-232

Craft ME (2015) Infectious disease transmission and contact networks in wildlife and livestock. Phil Trans R Soc B 370:20140107

Creel SR, Creel NM (1991) Energetics, reproductive suppression and obligate communal breeding in carnivores. Behav Ecol Sociobiol 28:263-270

Creel S, Creel NM, Mills MGL, Monfort SL (1997) Rank and reproduction in cooperatively breeding African wild dogs: behavioral and endocrine correlates. Behav Ecol 8:298-306

Dechmann DKN, Kalko EKV, Kerth G (2007) All-offspring dispersal in a tropical mammal with resource defense polygyny. Behav Ecol Sociobiol 61:1219-1228

Defanis E, Jones G (1995) The role of odor in the discrimination of conspecifics by pipistrelle bats. Anim Behav 49:835-839

Dunbar RIM (1983) Structure of gelada baboon reproductive units. 2 . Social relationships between reproductive females. Anim Behav 31:556-564

Englert AC, Greene MJ (2009) Chemically-mediated roostmate recognition and roost selection by Brazilian free-tailed bats (Tadarida brasiliensis). PLoS One 4:e7781

Farine DR (2013) Animal social network inference and permutations for ecologists in R using asnipe. Methods Ecol Evol 4:1187-1194

Farine DR (2017) A guide to null models for animal social network analysis. Methods Ecol Evol 8:1309-1320
Farine DR, Sheldon BC (2016) Social ecology of a woodland songbird community: from individual movements to the emergence of population social structure. bioRxiv. https://doi.org/10.1101/085944

Farine DR, Whitehead H (2015) Constructing, conducting and interpreting animal social network analysis. J Anim Ecol 84: 1144-1163

Fortuna MA, Popa-Lisseanu AG, Ibáñez C, Bascompte J (2009) The roosting spatial network of a bird-predator bat. Ecology 90:934-944

Freeberg TM, Dunbar RI, Ord TJ (2012) Social complexity as a proximate and ultimate factor in communicative complexity. Philos Trans R Soc B 367:1785-1801

Gager Y, Gimenez O, O'Mara MT, Dechmann DKN (2016) Group size, survival and surprisingly short lifespan in socially foraging bats. BMC Ecol 16:2

Garg KM, Chattopadhyay B, Ramakrishnan U (2018) Social structure in the harem-forming promiscuous fruit bat, Cynopterus sphinx, is the harem truly important? R Soc Open Sci 5:172024

Gillam EH, Chaverri G (2012) Strong individual signatures and weaker group signatures in contact calls of Spix's disc-winged bat, Thyroptera tricolor. Anim Behav 83:269-276

Gillam EH, Chaverri G, Montero K, Sagot M (2013) Social calls produced within and near the roost in two species of tent-making bats, Dermanura watsoni and Ectophylla alba. PLoS One 8:e61731

Girvan M, Newman MEJ (2002) Community structure in social and biological networks. Proc Natl Acad Sci U S A 99:7821-7826

Godinho LN, Lumsden LF, Coulson G, Griffiths SR (2015) Network analysis reveals cryptic seasonal patterns of association in Gould's wattled bats (Chalinolobus gouldii) roosting in bat-boxes. Behaviour 152:1079-2105

Greenwood PJ (1980) Mating systems, philopatry and dispersal in birds and mammals. Anim Behav 28:1140-1162

Günther L, Lopez MD, Knörnschild M, Reid K, Nagy M, Mayer F (2016) From resource to female defence: the impact of roosting ecology on a bat's mating strategy. R Soc Open Sci 3:160503

He P, Maldonado-Chaparro A, Farine DR (2019) The role of habitat configuration in shaping social structure: a gap in studies of animal social complexity. Behav Ecol Sociobiol. https://doi.org/10.1007/ s00265-018-2602-7

Heckel G, von Helversen O (2002) Male tactics and reproductive success in the harem polygynous bat Saccopteryx bilineata. Behav Ecol 13: 750-756

Hoppitt W, Farine DR (2018) Association indices for quantifying social relationships: how to deal with missing observations of individuals or groups. Anim Behav 136:227-238

Jarvis JUM (1981) Eusociality in a mammal - cooperative breeding in naked mole-rat colonies. Science 212:571-573

Johnson N, Arechiga-Ceballos N, Aguilar-Setien A (2014) Vampire bat rabies: ecology, epidemiology and control. Viruses 6:1911-1928

Kappeler PM (2019) A framework for studying social complexity. Behav Ecol Sociobiol. https://doi.org/10.1007/s00265-018-2601-8

Kerth G (2008) Causes and consequences of sociality in bats. Bioscience 58:737-746

Kerth G, König B (1999) Fission, fusion and nonrandom associations in female Bechstein's bats (Myotis bechsteinii). Behaviour 136:11871202

Kerth G, Morf L (2004) Behavioural and genetic data suggest that Bechstein's bats predominantly mate outside the breeding habitat. Ethology 110:987-999

Kerth G, Reckardt K (2003) Information transfer about roosts in female Bechstein's bats: an experimental field study. Proc R Soc Lond B 270:511-515

Kerth G, Safi K, König B (2002) Mean colony relatedness is a poor predictor of colony structure and female philopatry in the communally breeding Bechstein's bat (Myotis bechsteinii). Behav Ecol Sociobiol 52:203-210 
Kerth G, Perony N, Schweitzer F (2011) Bats are able to maintain longterm social relationships despite the high fission-fusion dynamics of their groups. Proc R Soc Lond B 278:2761-2767

Knörnschild M, Nagy M, Metz M, Mayer F, von Helversen O (2012) Learned vocal group signatures in the polygynous bat Saccopteryx bilineata. Anim Behav 84:761-769

Kudo H, Dunbar RIM (2001) Neocortex size and social network size in primates. Anim Behav 62:711-722

Lee PC (1987) Allomothering among African elephants. Anim Behav 35:278-291

Lewis SE (1995) Roost fidelity of bats: a review. J Mamm 76:481-496

Lewis SE (1996) Low roost-site fidelity in pallid bats: associated factors and effect on group stability. Behav Ecol Sociobiol 39:335-344

Lukas D, Clutton-Brock T (2012) Life histories and the evolution of cooperative breeding in mammals. Proc R Soc Lond B 279:4065-4070

MacKinnon KC, Fuentes A (2011) Primates, niche construction, and social complexity: the roles of social cooperation and altruism. In: Sussman RW, Cloninger CR (eds) Origins of altruism and cooperation. Springer, New York, pp 121-143

MacLeod KJ, Lukas D (2014) Revisiting non-offspring nursing: allonursing evolves when the costs are low. Biol Lett 10:20140378

McComb K, Moss C, Durant SM, Baker L, Sayialel S (2001) Matriarchs as repositories of social knowledge in African elephants. Science 292:491-494

McCracken GF (1987) Genetic structure of bat social groups. In: Racey PA, Fenton MB, Rayner JMV (eds) Recent advances in the study of bats. Cambridge University Press, Cambridge, pp 281-298

McCracken GF, Bradbury JW (1981) Social organization and kinship in the polygynous bat Phyllostomus hastatus. Behav Ecol Sociobiol 8:11-34

McCracken GF, Wilkinson GS (2000) Bat mating systems. In: Krutszch $\mathrm{PH}$, Crichton EG (eds) Reproductive biology of bats. Academic Press, New York, pp 321-362

Metheny JD, Kalcounis-Rueppell MC, Willis CKR, Kolar KA, Brigham RM (2007) Genetic relationships between roost-mates in a fissionfusion society of tree-roosting big brown bats (Eptesicus fuscus). Behav Ecol Sociobiol 62:1043-1051

Moehlman PD, Hofer H (1997) Cooperative breeding, reproductive suppression, and body mass in canids. In: Solomon NG, French JA (eds) Cooperative breeding in mammals. Cambridge University Press, New York, pp 76-128

Moller LM, Beheregaray LB, Harcourt RG, Krutzen M (2001) Alliance membership and kinship in wild male bottlenose dolphins (Tursiops aduncus) of southeastern Australia. Proc R Soc Lond B 268:1941-1947

Morrison DW (1979) Apparent male defense of tree hollows in the bat, Artibeus jamaicensis. J Mammal 60:11-15

Moussy C, Hosken DJ, Mathews F, Smith GC, Aegerter JN, Bearhop S (2013) Migration and dispersal patterns of bats and their influence on genetic structure. Mamm Rev 43:183-195

Nagy M, Knörnschild M, Voigt CC, Mayer F (2012) Male greater sacwinged bats gain direct fitness benefits when roosting in multimale colonies. Behav Ecol 23:597-606

Nagy M, Günther L, Knörnschild M, Mayer F (2013) Female-biased dispersal in a bat with a female-defence mating strategy. Mol Ecol 22:1733-1745

Newman MEJ (2004) Analysis of weighted networks. Phys Rev E 70: 056131

Newman MEJ (2006) Modularity and community structure in networks. Proc Natl Acad Sci U S A 103:8577-8582

Omer DB, Maimon SR, Las L, Ulanovsky N (2018) Social place-cells in the bat hippocampus. Science 359:218-224

Ortega J, Arita HT (2000) Defence of females by dominant males of Artibeus jamaicensis (Chiroptera: Phyllostomidae). Ethology 106: 395-407

Ortega J, Maldonado JE, Wilkinson GS, Arita HT, Fleischer RC (2003) Male dominance, paternity, and relatedness in the Jamaican fruiteating bat (Artibeus jamaicensis). Mol Ecol 12:2409-2415
Packer C, Lewis S, Pusey A (1992) A comparative analysis of nonoffspring nursing. Anim Behav 43:265-281

Park SR (1991) Development of social structure in a captive colony of the common vampire bat, Desmodus rotundus. Ethology 89:335-341

Parsons KM, Durban JW, Claridge DE, Balcomb KC, Noble LR, Thompson PM (2003) Kinship as a basis for alliance formation between male bottlenose dolphins, Tursiops truncatus, in the Bahamas. Anim Behav 66:185-194

Parsons KM, Balcomb KC, Ford JKB, Durban JW (2009) The social dynamics of southern resident killer whales and conservation implications for this endangered population. Anim Behav 77:963-971

Parsons JG, SKA R, Shilton LA (2011) Roost fidelity in spectacled flying-foxes Pteropus conspicillatus: implications for conservation and management. In: Law B, Eby P, Lunney D, Lumsden L (eds) The biology and conservation of Australasian bats. Royal Zoological Society of NSW, Mosman, pp 66-71

Pasquaretta C, Leve M, Claidiere N et al (2014) Social networks in primates: smart and tolerant species have more efficient networks. Sci Rep 4:7600

Patriquin KJ, Leonard ML, Broders HG, Garroway CJ (2010) Do social networks of female northern long-eared bats vary with reproductive period and age? Behav Ecol Sociobiol 64:899-913

Patriquin KJ, Palstra F, Leonard ML, Broders HG (2013) Female northern myotis (Myotis septentrionalis) that roost together are related. Behav Ecol 24:949-954

Payne K (2003) Sources of social complexity in the three elephant species. In: de Waal FBM, Tyack PL (eds) Animal social complexity. Harvard University Press, Cambridge, pp 57-85

Podgorski T, Lusseau D, Scandura M, Sonnichsen L, Jedrzejewska B (2014) Long-lasting, kin-directed female interactions in a spatially structured wild boar social network. PLoS One 9:e99875

Pretzlaff I, Kerth G, Dausmann KH (2010) Communally breeding bats use physiological and behavioural adjustments to optimise daily energy expenditure. Naturwissenschaften 97:353-363

Racey PA, Entwhistle AC (2000) Life history and reproductive strategies of bats. In: Krutzsch PH, Crichton EG (eds) Reproductive biology of bats. Academic Press, New York, pp 363-414

Roberts BJ, Catterall CP, Eby P, Kanowski J (2012) Long-distance and frequent movements of the flying-fox Pteropus poliocephalus: implications for management. PLoS One 7:e42532

Rossiter SJ, Jones G, Ransome RD, Barratt EM (2002) Relatedness structure and kin-biased foraging in the greater horseshoe bat (Rhinolophus ferrumequinum). Behav Ecol Sociobiol 51:510-518

Roulin A (2002) Why do lactating females nurse alien offspring? A review of hypotheses and empirical evidence. Anim Behav 63:201-208

Safi K, Kerth G (2003) Secretions of the interaural gland contain information about individuality and colony membership in the Bechstein's bat. Anim Behav 65:363-369

Sah P, Leu ST, Cross PC, Hudson PJ, Bansal S (2017) Unraveling the disease consequences and mechanisms of modular structure in animal social networks. Proc Natl Acad Sci U S A 114:4165-4170

Schino G, Aureli F (2010) The relative roles of kinship and reciprocity in explaining primate altruism. Ecol Lett 13:45-50

Schöner CR, Schöner MG, Kerth G (2010) Similar is not the same: social calls of conspecifics are more effective in attracting wild bats to day roosts than those of other bat species. Behav Ecol Sociobiol 64: 2053-2063

Seyfarth RM, Cheney DL (1984) Grooming, alliances and reciprocal altruism in vervet monkeys. Nature 308:541-543

Shizuka D, Farine DR (2016) Measuring the robustness of network community structure using assortativity. Anim Behav 112:237-246

Silk JB (2007) Social components of fitness in primate groups. Science 317:1347-1351

Silk JB, Alberts SC, Altmann J (2004) Patterns of coalition formation by adult female baboons in Amboseli, Kenya. Anim Behav 67:573-582 
Storz JF (2000) Social structure of a polygynous tent-making bat, Cynopterus sphinx (Megachiroptera). J Zool 251:151-165

Storz JF, Bhat HR, Kunz TH (2001a) Genetic consequences of polygyny and social structure in an Indian fruit bat, Cynopterus sphinx. I. Inbreeding, outbreeding, and population subdivision. Evolution 55:1215-1223

Storz JF, Bhat HR, Kunz TH (2001b) Genetic consequences of polygyny and social structure in an Indian fruit bat, Cynopterus sphinx. II. Variance in male mating success and effective population size. Evolution 55:1224-1232

Trune DR, Slobodchikoff CN (1976) Social effects of roosting on the metabolism of the pallid bat (Antrozous pallidus). J Mammal 57: 656-663

Tuttle MD, Stevenson D (1982) Growth and survival of bats. In: Kunz TH (ed) Ecology of bats. Plenum Press, New York, pp 105-150

Wang J (2011) COANCESTRY: a program for simulating, estimating and analysing relatedness and inbreeding coefficients. Mol Ecol Resour 11:141-145

Wang J (2017) Estimating pairwise relatedness in a small sample of individuals. Heredity 119:302-313

Whitehead H (1995) Investigating structure and temporal scale in social organizations using identified individuals. Behav Ecol 6:199-208

Whitehead H (2008) Analyzing animal societies: quantitative methods for vertebrate social analysis. Chicago University Press, Chicago

Whitehead H (2009) SOCPROG programs: analysing animal social structures. Behav Ecol Sociobiol 63:765-778

Wilkinson GS (1984) Reciprocal food sharing in vampire bats. Nature 309:181-184

Wilkinson GS (1985a) The social organization of the common vampire bat. I. Pattern and cause of association. Behav Ecol Sociobiol 17: $111-121$
Wilkinson GS (1985b) The social organization of the common vampire bat. II. Mating system, genetic structure, and relatedness. Behav Ecol Sociobiol 17:123-134

Wilkinson GS (1986) Social grooming in the common vampire bat, Desmodus rotundus. Anim Behav 34:1880-1889

Wilkinson GS (1987) Altruism and cooperation in bats. In: Racey PA, Fenton MB, Rayner JMV (eds) Recent advances in the study of bats. Cambridge University Press, Cambridge, pp 299-323

Wilkinson GS (1992a) Communal nursing in evening bats. Behav Ecol Sociobiol 31:225-235

Wilkinson GS (1992b) Information transfer at evening bat colonies. Anim Behav 44:501-518

Wilkinson GS, Boughman JW (1998) Social calls coordinate foraging in greater spear-nosed bats. Anim Behav 55:337-350

Wilkinson GS, South JM (2002) Life history, ecology and longevity in bats. Aging Cell 1:124-131

Wilkinson GS, Carter GG, Bohn KM, Adams DM (2016) Non-kin cooperation in bats. Philos Trans R Soc B 371:20150095

Wiszniewski J, Brown C, Moller LM (2012) Complex patterns of male alliance formation in a dolphin social network. J Mammal 93:239-250

Wittemyer G, Okello JB, Rasmussen HB, Arctander P, Nyakaana S, Douglas-Hamilton I, Siegismund HR (2009) Where sociality and relatedness diverge: the genetic basis for hierarchical social organization in African elephants. Proc R Soc Lond B 276:3513-3521

Worthington-Wilmer J, Barratt EM (1996) A non-lethal method of tissue sampling for genetic studies of chiropterans. Bat Res News 37:1-3

Zeus VM, Reusch C, Kerth G (2018) Long-term roosting data reveal a unimodular social network in large fission-fusion society of the colony-living Natterer's bat (Myotis nattereri). Behav Ecol Sociobiol 72:99-112 